\title{
Improvement of Requirement Elicitation Process through Cognitive Psychology
}

\author{
Sana Fatima, Qamar Uddin Khand, Jawaid Ahmed Siddique \\ Department of Computer Science, Sukkur IBA, Pakistan \\ sana.fatima@iba-suk.edu.pk, qamar@iba-suk.edu.pk, jawaid@iba-suk.edu.pk
}

\author{
Zulfiqar Ali Memon \\ NU FAST Karachi, Pakistan \\ zulfiqar.memon@nu.edu.pk
}

\begin{abstract}
Proper requirement elicitation is necessary for client satisfaction along with the overall project success, but requirement engineers face problems in understanding user requirements and the users of the required system fail to make requirement engineering team understand what they actually want. It is then responsibility of requirement engineers to extract proper requirements. This paper discusses how to use cognitive psychology and learning style models (LSM) to understand the psychology of clients. Moreover, it also discusses usage of proper elicitation technique according to one's learning style and gather the right requirements.
\end{abstract}

Keywords: Cognitive Psychology, Learning Style Models (LSM), Requirement Elicitation Techniques

\section{Introduction}

Software industry is trying their best to build such softwares that earn businesses maximum profit within reasonable cost and time because the technology in market changes quickly. Software engineers with the help of project managers are responsible for building such systems/software that a customer requires. Requirement elicitation is considered as the most critical and most essential part of software development because errors at this stage spread through whole development process and error mitigation at later stages is tough; which might lead to software failure. Users who play important role mostly belong to non IT background, so it is hard for them to express the requirements. Hence, the requirements collected are incomplete, ambiguous and inconsistent. That is why requirement engineers have to understand what users have failed to convey and understand which users can't simply put into words. The quality of the requirements is greatly influenced by usage of proper elicitation technique in appropriate situations. It doesn't prove that the technique which fits with one user might prove to be better for some other user because everyone has their own level of understanding [1].

Often, stakeholders are interviewed about their requirements or asked to write them down, but this approach rarely uncovers the real requirements that reflect a customer's true interests or needs. People have different perception of the world, they think and feel 
differently according to their personal experience and preferences [2]. On the other hand, there are several other fields which direct requirement elicitation process towards improvement. Cognitive psychology is the field of study in HCI that deals with the

Table 1: Different learning style.

\begin{tabular}{|c|c|}
\hline $\begin{array}{l}\text { Type of } \\
\text { Learner }\end{array}$ & Preferences \\
\hline Sensing & $\begin{array}{l}\text { Prefers concrete thinking and } \\
\text { practicality, concerned with } \\
\text { the facts and procedures }\end{array}$ \\
\hline Intuitive & $\begin{array}{l}\text { Prefers conceptual thinking, } \\
\text { innovative, concerned with } \\
\text { theories and meanings }\end{array}$ \\
\hline Visual & $\begin{array}{l}\text { Prefers a visual representation, } \\
\text { diagrams, charts, and graphs }\end{array}$ \\
\hline Verbal & $\begin{array}{l}\text { Prefers written or spoken } \\
\text { explanations }\end{array}$ \\
\hline Active & $\begin{array}{l}\text { Prefers to try new things out, } \\
\text { likes working in groups }\end{array}$ \\
\hline Reflective & $\begin{array}{l}\text { Prefers thinking things out, } \\
\text { likes to work alone or with } \\
\text { familiar partner }\end{array}$ \\
\hline Sequential & $\begin{array}{l}\text { Preferably linear thinking, } \\
\text { orderly, learn in small } \\
\text { incremental steps }\end{array}$ \\
\hline Global & $\begin{array}{l}\text { Preferably general thinking } \\
\text { and systems thinkers, learn in } \\
\text { great leaps }\end{array}$ \\
\hline
\end{tabular}

thinking mind and is concerned with how we attend and gain information about the world with a goal to develop a theory of intelligent systems [3]. This research study is about mapping elicitation technique that matches an individual's learning style preference or user's level of understanding.

"The Felder-Silverman Learning Styles Model" is based on taking learning style into account. While some people say that learning style and educational designs (especially elearning environments) must accommodate different learning paths. It is great to teach in a way that increases learning for all students. This is challenging because students learn in various ways.

Learners with a strong preference for a specific learning style may have difficulties in learning, if the teaching style does not match with their learning style preference [4].This model grouped people on the basis of how they comprehend information, how they understand better and how their brain works. It divided people on how they prefer information to be presented in front of them. This model further proposed that there are four dimensions of learning styles. It concluded that the teaching style should be adjusted according to specific learning preference of a person which is shown in Table 1.

Researcher has used the same idea for eliciting requirements. The idea is to take into account visual-verbal, active-reflective preferences (only two from four) and then chooses a set of stakeholders with particular learning style preference then maps an elicitation technique that fits in accordance with individual learning style preference. This research paper is basically a survey conducted to prove author's point of view.

\section{Related Work}

A literature review was conducted to explore which authors have worked in the same field. Every author has given their own ideas and proof on how to get a better requirement set using cognitive psychology and some have generally discussed about taking a keen look at elicitation process as whole. Rather than a question and answer session for collecting software and system 
requirements, requirements elicitation is more complicated then what it appears to be [5].Generally, the systems requirements identification stage is one of the most important integral parts of the process, that can "make or break" the project. "60\% to $80 \%$ of errors originate in the user requirements and functional specification" stage [6]. Some authors did relative work using learning style model, their study depicts requirements prioritization where various stakeholders/requirement evaluators are involved. They found out that many conflicts arise in finalizing requirements from a set of already defined requirements, as stakeholders have different knowledge, specialties, and needs of a system. Therefore, reaching consensus on requirement definition is tricky area.

To overcome this situation, they provided a conflict resolution model that considers stakeholders' viewpoints, their work mainly concentrates on defining cognitive weights to priorities requirements. Cognitive weight is a number that represents individual's learning style preference along with elicitation technique he has chosen. The base of their model is goal based method and it is basically a controlled experiment conducted from 24 students of academia who have some experience in requirement engineering processes [1]. Other authors also use cognitive psychology to prioritize requirements. They argue that the requirement engineering should provide a methodological framework applicable to the interpretation and understanding of the terminology used by stakeholders, their views and objectives. That is why Cognitive Psychology provides a conceptual framework, to deal with the descriptions of the stakeholders requirements.

They suggest that stakeholders with same preferences about requirements should be clustered together. They add that it is hard to find out requirements as stakeholders are biased by their owns need so in order to get the requirements that reflects the actual needs can be discovered through the use of semantic memory. In order to get the priority requirements a picture of the stakeholders' semantic memory is to be used as a conceptual structure. Hence their study is about detection of clusters of stakeholders preferences revealed via the Analytic Hierarchy Process (AHP) and the cluster detection is carried out using Self Organizing Maps (SOM) [2], whereas our research study is different from the two above mentioned research studies in a sense that this article depicts how to gather requirements at client site using learning style model, for that a survey was conducted from different requirement analysts in Pakistan and the tool used to prove or disprove hypothesis is SPSS. The only similarity is the usage of cognitive psychology and learning style model.

\section{Survey Structure}

Sole motivation of this survey is to prove author's opinion on how to find out what a customer actually requires. When it comes to choosing requirement elicitation techniques for clients, there is no particular source on when to use which technique. Requirement analysts usually choose techniques on what they think would suit better in the given circumstances. As a result, requirements gathered are vague and ambiguous. So analyst tend to change the technique once they realize the previous technique failed to grasp the true set of requirements, this has a negative effect on the cost, time and efforts of the overall project.

Author's argument is to choose a technique after finding out the learning style preference of targeted clients, this gives an insight of which techniques are not be used on particular client. So the hypothesis formulated is;

H0: There is no significant effect of mapping Requirement Elicitation Techniques according to people's preferences on getting better requirements set 
H1: Mapping Requirement Elicitation Techniques according to people's preferences have positive effect on getting better requirements set

\subsection{Survey Design}

A survey was conducted to see what techniques are practiced when it comes to requirement elicitation, whether they follow typical bookish techniques or they have their own standard practices, whether they have a solid reason for choosing a technique or not. After that a workshop was conducted for another round of questions and to put forward author's idea and see if it results in better requirement set or not and also to decide which set of techniques to be paired with each preference type, this is shown in Table 2. Random sampling is selected for survey design because initially all of the software houses were selected in Pakistan region, out of which 45 requirement analyst responded and every requirement analyst had minimum of two year experience in the relevant filed.

Survey consisted of a series of questions items and a few interviews. Questions that were asked in first round were about feedback practices in the field and he questions were about, which technique they use mostly, whether they choose a technique on the basis of experience, do they change a technique when they realize the previous technique didn't provide with the required requirements and if the cause of failure is poor communication with the clients and if they want to merge some concepts of psychology with Requirement engineering for better elicitation. In the second round, it was asked to apply set of tasks (mentioned in the section IV.) and see if they find it better to merge cognitive psychology with Requirement elicitation process and help requirement analysts understand stakeholder better and what they suggest should be altered/ added in different elicitation techniques (open ended question).

\section{Mapping Learning Style and Requirement Techniques}

This research process requires requirement engineering team to perform following task when they are at client site for gathering/ discussed requirements. This section was discussed with requirement analyst in the workshop conducted and the tasks concluded were as follows,

Table 2: Elicitation Techniques that are Mapped According to Learning Style Preference

\begin{tabular}{|c|c|}
\hline Interview & \multirow{3}{*}{$\begin{array}{l}\text { Reflective } \\
\text { People }\end{array}$} \\
\hline Ethnography & \\
\hline Meetings & \\
\hline Brainstorming & \multirow{4}{*}{$\begin{array}{l}\text { Active } \\
\text { people }\end{array}$} \\
\hline Focus groups & \\
\hline $\begin{array}{c}\text { Joint application } \\
\text { development }\end{array}$ & \\
\hline Facilitated sessions & \\
\hline Scenarios & \multirow{4}{*}{$\begin{array}{l}\text { Verbal } \\
\text { People }\end{array}$} \\
\hline User stories & \\
\hline Story board & \\
\hline Questionnaire & \\
\hline Data modelling & \multirow{4}{*}{$\begin{array}{l}\text { Visual } \\
\text { People }\end{array}$} \\
\hline Use cases & \\
\hline $\begin{array}{c}\text { Data flow diagrams/ } \\
\text { UML }\end{array}$ & \\
\hline Prototyping & \\
\hline
\end{tabular}

Task 1: Grouping potential stakeholders/end users who directly take part into requirement elicitation.

Task 2: Find out how their brain prefers information to be presented and what is their learning style preference using the index of the Felder Silverman Learning Styles Model which is basically a questionnaire that one has to fill. 
After the results, a person can be visual or verbal but not both. And a person can be active or reflective not both. Which means a person can be visual and active, visual and reflective, verbal and active, verbal and reflective and a balanced person with same visual and verbal values and different active or reflective values. Other balanced people include having same active or reflective but different visual and verbal values. And the last people are the ones with balanced choices on both the preferences. So there can be total of seven type of brains people can have.

Task 3: Rank users and categorize them as visual, verbal, active and reflective person according to the results.

Task 4: Choose an elicitation technique that best fits each individual's learning style preference. These techniques are mapped on the basis of characteristics one's brain has.

Mapping was decided in the workshop. The mapping shown in Table 2.

\section{Conclusion and Results}

This research paper discusses how to improve requirement elicitation process by integrating the Felder-Silverman Learning Styles Model, this model is basically taken from cognitive psychology and is merged with traditional elicitation techniques for getting better requirement set. In order to prove the author's that they choose a technique on the basis of experience which is $71.1 \%, 40$ people said that they change the technique once they realize previous technique failed to grasp true requirements which is $88.9 \%$ and 40 out of 45 said that problems in requirement elicitation.

Claim a survey was conducted. For the first round of questions, out of 45 people 32 said recused by poor communication with the clients which is $88.9 \%$, the results are mentioned in Table 3. Results were generated using SPSS Results prove that analysts in software houses of Pakistan do not have a solid ground for choosing requirement and due to poor communication they change the elicitation technique when the previous one fails. Second round proves or disproves the hypothesis. McNemar Test was performed with confidence interval of $95 \%$ to see if there is any difference in opinions after first and second round of question. The result presented clearly rejects the null hypothesis and proves that merging cognitive psychology with requirement elicitation helps in getting better requirement set. The results are summarized in Table 4.

\section{Table 3: Elicitation techniques that are mapped according to learning style preference}

Choose_RET_On_PersonalExperience

\begin{tabular}{|c|c|c|c|c|c|}
\hline & & Frequency & Percent & Valid Percent & $\begin{array}{c}\text { Cumulative } \\
\text { Percent }\end{array}$ \\
\hline \multirow[t]{3}{*}{ Valid } & No & 13 & 28.9 & 28.9 & 28.9 \\
\hline & Yes & 32 & 71.1 & 71.1 & 100.0 \\
\hline & Total & 45 & 100.0 & 100.0 & \\
\hline
\end{tabular}

Change_RET_if_Previous_fail

\begin{tabular}{|rl|r|r|r|r|}
\hline & & Frequency & Percent & Valid Percent & $\begin{array}{c}\text { Cumulative } \\
\text { Percent }\end{array}$ \\
\hline Valid & No & 5 & 11.1 & 11.1 & 11.1 \\
& Yes & 40 & 88.9 & 88.9 & 100.0 \\
& Total & 45 & 100.0 & 100.0 & \\
\hline
\end{tabular}

Product_failure_problems_in_communication_with_customer

\begin{tabular}{|c|c|c|c|c|c|}
\hline & & Frequency & Percent & Valid Percent & $\begin{array}{c}\text { Cumulative } \\
\text { Percent }\end{array}$ \\
\hline \multirow[t]{3}{*}{ Valid } & No & 5 & 11.1 & 11.1 & 11.1 \\
\hline & Yes & 40 & 88.9 & 88.9 & 100.0 \\
\hline & Total & 45 & 100.0 & 100.0 & \\
\hline
\end{tabular}


Table 4: Summarized Result after Applying McNemar Test

Merge_Psychology_with_RET_before *Cognitive_Pstchology_With_RET_After Crosstabulation

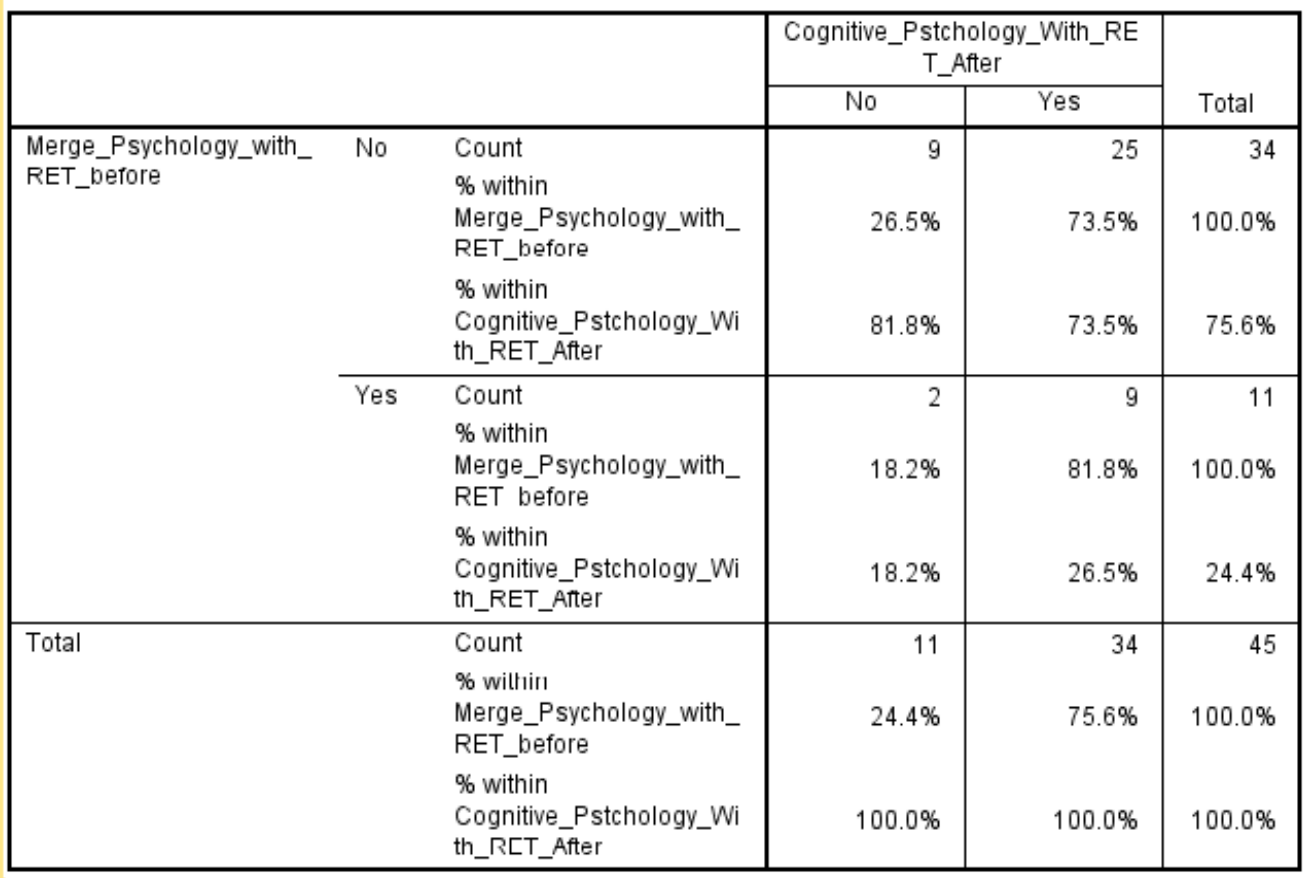

Chi-Square Tests

\begin{tabular}{|l|r|c|}
\hline & Value & $\begin{array}{c}\text { Exact Siq. (2- } \\
\text { sided) }\end{array}$ \\
\hline $\begin{array}{l}\text { McNemar Test } \\
\text { N of Valid Cases }\end{array}$ & 45 & $.000^{\mathrm{a}}$ \\
\hline
\end{tabular}

a. Binomial distribution used

\section{References}

[1] N. M. Carod, "A Cognitive Psychology Approach for Balancing Elicitation Goals," in Int. Conf. on Cognitive Informatics (ICCI'07), 2007.

[2] A. Chechich, "Cognitive-Driven Requirement Prioritaization : A case study," in Cognitive Informatics (ICCI'10), 2010.

[3] V. C. a. Y. Wang, "FROM COGNITIVE PSYCHOLOGY TO COGNITIVE
INFORMATICS," in Second IEEE International Conference on Cognitive Informatics, 2003.

[4] R. M. F. a. J. SPURLIN, "Applications, Reliability and Validity of the Index of Learning Styles*," International Journal of Engineering Science, vol. 21, pp. 103-112, 2005.

[5] L. RAMINGWONG, "A REVIEW OF REQUIREMENTS ENGINEERING PROCESSES PROBLEMS AND MODELS," International Journal of Engineering Science and Technology (IJEST), vol. 4, no. 6, pp. 2997-3002, 2012. 